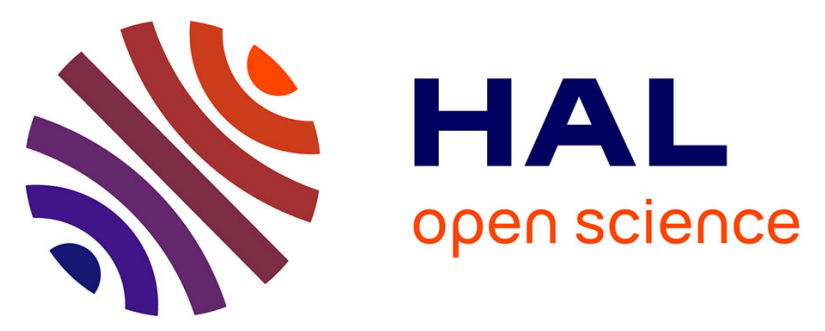

\title{
Asp-218 participates with asp-213 to bind a ca2+ atom into the S1 subsite of aminopeptidase A: a key element for substrate specificity
}

Cédric Claperon, Raphael Rozenfeld, Xavier Iturrioz, Nicolas Inguimbert, Mayumi Okada, Bernard P. Roques, Bernard Maigret, Catherine

\author{
Llorens-Cortes
}

\section{To cite this version:}

Cédric Claperon, Raphael Rozenfeld, Xavier Iturrioz, Nicolas Inguimbert, Mayumi Okada, et al.. Asp-218 participates with asp-213 to bind a ca2+ atom into the S1 subsite of aminopeptidase A: a key element for substrate specificity. Biochemical Journal, 2008, 416 (1), pp.37-46. 10.1042/BJ20080471 . hal-00478991

\section{HAL Id: hal-00478991 \\ https://hal.science/hal-00478991}

Submitted on 30 Apr 2010

HAL is a multi-disciplinary open access archive for the deposit and dissemination of scientific research documents, whether they are published or not. The documents may come from teaching and research institutions in France or abroad, or from public or private research centers.
L'archive ouverte pluridisciplinaire HAL, est destinée au dépôt et à la diffusion de documents scientifiques de niveau recherche, publiés ou non, émanant des établissements d'enseignement et de recherche français ou étrangers, des laboratoires publics ou privés. 


\section{ASP-218 PARTICIPATES WITH ASP-213 TO BIND A $\mathrm{Ca}^{2+}$ ATOM INTO THE S1 SUBSITE OF AMINOPEPTIDASE A: A KEY ELEMENT FOR SUBSTRATE SPECIFICTY}

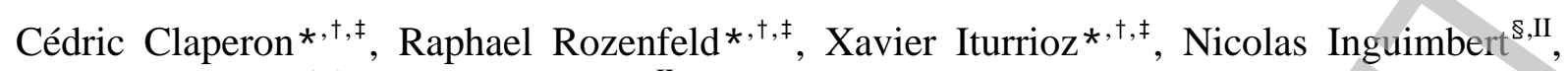
Mayumi Okada $^{*, \dagger, \ddagger}$, Bernard Roques ${ }^{\S, I I}$, Bernard Maigret ${ }^{\top}$ and Catherine Llorens-Cortes ${ }^{*}, \dagger, \neq$ $\S$

From * INSERM, U691, Paris, FR-75005 France; ${ }^{\dagger}$ Collège de France, Paris, FR-75005 France; ${ }^{\ddagger}$ Université Pierre et Marie Curie, Paris, FR-75005 France; ${ }^{\S}$ INSERM, U640, Paris, FR-75005 France; II Université René Descartes, Paris, FR-75005 France; ^ CNRS, UMR 7503, Vandoeuvre Les Nancy, FR-54506, France; Laboratoire Lorrain de Recherche en Informatique et ses applications (LORIA).

To whom correspondence should be addressed: Catherine Llorens-Cortes, 11 place Marcelin Berthelot, 75231 Paris Cedex 05, France.

Phone: 331442716 63; Fax: 331442716 67; E-mail: c.llorens-cortes@college-de-france.fr

Running title: $\mathrm{Ca}^{2+}$ binding site in APA 


\section{SYNOPSIS}

Aminopeptidase A (EC 3.4.11.7, APA) is a membrane-bound zinc metallopeptidase, also activated by $\mathrm{Ca}^{2+}$, involved in the formation of brain angiotensin III, which exerts a tonic stimulatory action on the central control of blood pressure in hypertensive animals.

In the three-dimentional model of the ectodomain of mouse APA, we docked the specific APA inhibitor glutamate phosphonate, in the presence of $\mathrm{Ca}^{2+}$. The model showed the presence of one $\mathrm{Ca}^{2+}$ atom into an hydrophilic pocket corresponding to the S1 subsite in which the lateral chain of inhibitor is pointing. In this pocket, the $\mathrm{Ca}^{2+}$ atom was hexacoordinated with the acidic side chains of Asp-213 and Asp-218, the carbonyl group of Glu-215 and three water molecules, one of them being engaged in a hydrogen bond with the negatively charged carboxylate side chain of the inhibitor. Mutagenic replacement of Asp-213 and Asp-218 with a conservative residue maintained the ability of mutated APAs to be activated by $\mathrm{Ca}^{2+}$. However, the replacement by a non conservative residue abolished this property, demonstrating the crucial role of these residues in $\mathrm{Ca}^{2+}$ binding. We also showed the involvement of these residues in the strict specificity of APA in the presence of $\mathrm{Ca}^{2+}$ for Nterminal acidic residues from substrates or inhibitors, since mutagenic replacement of Asp213 and Asp-218 induced a decrease of the inhibitory potencies of inhibitors homologous to acidic residues. Finally, this led to rationally design a new potent APA inhibitor, NI926 (Ki = $70 \mathrm{nM}$ ), which allowed to precisely localize Asp-213 at the entrance and Asp-218 at the bottom of the S1 subsite. Altogether, these data provide new insight into the organization and functional role of the APA S1 subsite and will allow to design a pharmacophore of inhibitor, helpful for the development of a new generation of APA inhibitors as central-acting antihypertensive agents.

KEY WORD: monozinc aminopeptidase; calcium binding site; hypertension; inhibitor design; molecular modeling / site directed mutagenesis.

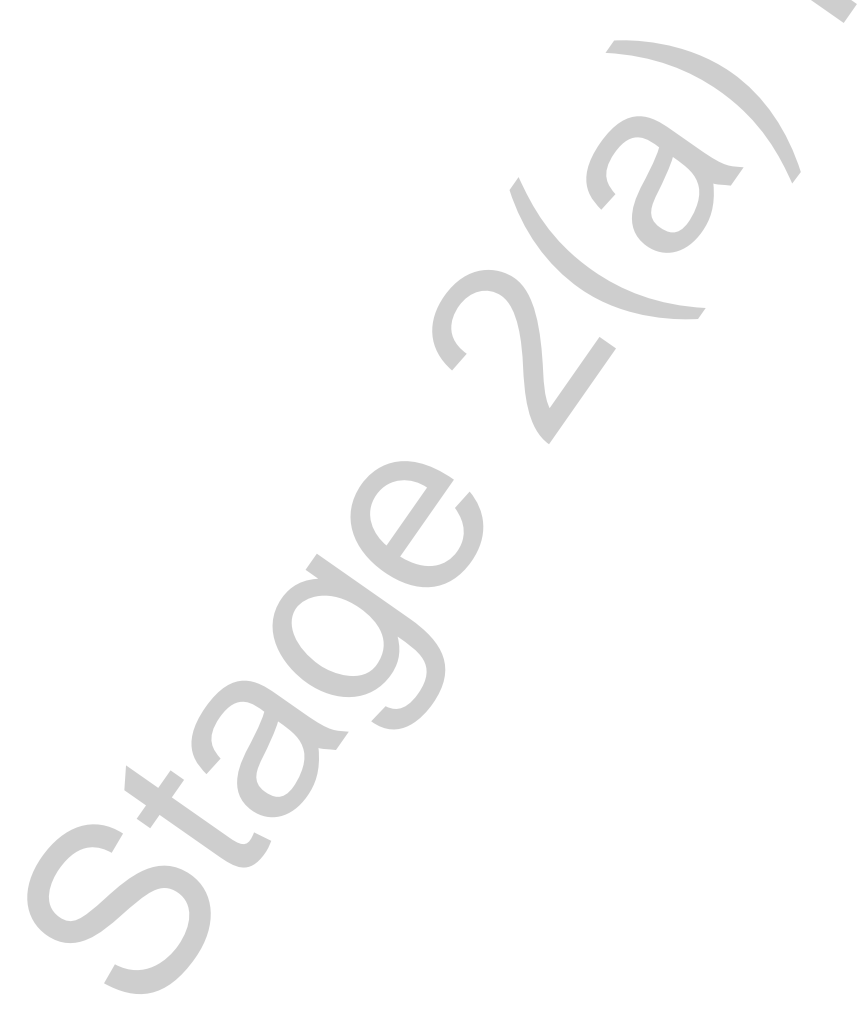




\section{INTRODUCTION}

Aminopeptidase A (EC 3.4.11.7, APA) is a $160 \mathrm{kDa}$ homodimeric type II membrane-bound aminopeptidase from the MA clan of the gluzincin family of metalloproteases. This enzyme preferentially cleaves the N-terminal glutamyl or aspartyl residue from peptide substrates such as angiotensin II (Ang II) and cholecystokinin-8 in vitro [1, 2]. APA is expressed in various tissues, including the renal and intestinal brush border epithelial cells and vascular endothelium [3]. APA has been identified in several brain nuclei involved in the control of body fluid homeostasis and cardiovascular function, together with other components of the brain renin-angiotensin system [4]. Studies using specific and selective APA inhibitors [5] have demonstrated that, in vivo, APA is responsible for the conversion of brain Ang II to angiotensin III (Ang III) [6] and that brain Ang III exerts a tonic stimulatory effect on the central control of blood pressure in hypertensive animals $[7,8]$. The inhibition of central APA with specific and selective inhibitors therefore leads to a large decrease in blood pressure in alert hypertensive rats [7, 8], suggesting that brain APA may be an interesting candidate target for the treatment of hypertension [9,10], and justifying studies of the active site of this enzyme.

Based on the X-ray crystal structure of leukotriene A4 hydrolase/aminopeptidase (EC 3.3.2.6, LTA4H) [11] and the functional data collected in our previous site-directed mutagenesis studies on APA [12-17], we built a three-dimensional (3D) model of the mouse APA ectodomain from residues 79 to 559 [18], including the catalytic domain of the enzyme [19]. In the 3D model of the APA active site, the zinc atom is coordinated by the two histidine residues (His-385 and His-389) of the HEXXH motif [17], a water molecule and Glu-408, which has been shown to be the third zinc ligand [16]. We then docked into the active site a potent and selective APA inhibitor, 4-amino-4-phosphobutyric acid (glutamate phosphonate), which behaves as a transition state analog [20]. Analysis of the APA/glutamate phosphonate complex confirmed the involvement of Tyr-471 in transition state stabilization [14] and that of Glu-352 and Glu-215 in the exopeptidase specificity of APA [15, 21]. Comparison of the APA structure deduced from our model with the recently resolved X-ray crystal structure of aminopeptidase N (EC 3.4.11.2, APN) [22-24] — another monozinc aminopeptidase revealed high levels of similarity in the organization of the active sites of APN and APA, supporting the use of our model to further investigate the mechanism of APA catalytic activity.

One of the key features of APA is its stimulation by $\mathrm{Ca}^{2+}$. Danielsen et al. [25] showed that each APA monomer contains one $\mathrm{Ca}^{2+}$ atom. The enzymatic activity of APA with substrates bearing acidic amino acids at their N-termini increases by a factor of 3 to 5 when $\mathrm{Ca}^{2+}$ concentration rises from 0 to $4 \mathrm{mM}[13,26]$. The stimulation of APA activity by $\mathrm{Ca}^{2+}$ is due to the greater affinity of APA for acidic substrates, with no significant difference in the rate of hydrolysis between acidic and non acidic substrates [13, 25, 27]. $\mathrm{Ca}^{2+}$ not only enhances the hydrolysis by APA of N-terminal acidic residues from substrates, but also inhibits the hydrolysis of N-terminal neutral or basic residues [28]. Danielsen et al. suggested that $\mathrm{Ca}^{2+}$ binds to the S1 subsite of APA and interacts with the side chain carboxylate of the P1 residue, ensuring the specificity of APA for substrates with N-terminal acidic residues [25].

Similarly, $\mathrm{Ca}^{2+}$ increases the affinity of APA for inhibitors with an acidic side chain and impairs the binding of inhibitors possessing a basic side chain in the P1 position [13]. Moreover, greater acidity of the P1 side chain of inhibitors renders these compounds more selective for APA than for APN, as illustrated by the greater selectivity of EC33 - two orders of magnitude greater than that of glutamate thiol (equipotent against both APA and 
APN) - after replacement of the carboxylate function of glutamate thiol by a sulfonate [5]. This difference is accounted for by the stronger interaction of $\mathrm{Ca}^{2+}$ with the sulfonate side chain of EC33, than of $\mathrm{Ca}^{2+}$ ion and the carboxylate side chain of glutamate thiol. These findings support the hypothesis that $\mathrm{Ca}^{2+}$ modulates the substrate specificity of APA, increasing its preference for acidic substrates. They also raise the possibility that variations in extracellular $\mathrm{Ca}^{2+}$ concentrations determine the nature of the substrate hydrolyzed by APA in vivo, thereby regulating APA function.

We used a combination of molecular modeling, site-directed mutagenesis, molecular design and organic chemistry to identify and characterize the residues constituting the $\mathrm{Ca}^{2+}$ binding site of APA. The introduction of a $\mathrm{Ca}^{2+}$ atom into the 3D model of the APA active site revealed an interaction of this ion with Asp-213 and Asp-218. We then used site-directed mutagenesis to confirm the functional role of Asp-213 and Asp-218. We first ensured that the mutated enzymes were processed similarly to wild-type APA and had a similar subcellular distribution. We then biochemically and kinetically characterized purified recombinant wildtype and mutated enzymes and determined their sensitivity to $\mathrm{Ca}^{2+}$ and various inhibitors. The design and synthesis of a potent new APA inhibitor, based on the 3D model, made it possible to localize precisely Asp-218 within the $\mathrm{Ca}^{2+}$ binding site. 


\section{Materials}

\section{MATERIALS AND METHODS}

Restriction endonucleases and DNA-modifying enzymes were obtained from New England Biolabs Inc. (Hitchin, USA) and were used according to the manufacturer's instructions. The Expand high-fidelity Taq polymerase PCR system was purchased from Roche Molecular Biochemicals (Mannheim, Germany). The liposomal transfection reagent, Lipofectamine 2000, the pcDNA 3.1-His vector and the monoclonal anti-Xpress antibody (anti-Xpress mAb) were purchased from Invitrogen (Groningen, Netherlands). The horseradish peroxydaseconjugated goat anti-mouse antibody was purchased from Sigma-Aidrich (Germany). Immobilized cobalt affinity columns (Talon) were obtained from CLONTECH (Heidelberg, Germany). The synthetic substrate $\alpha$-L-glutamyl-ß-naphthylamide (GluNA) was purchased from Bachem (Bunderdorf, Switzerland).

\section{Methods}

Modelling of the APA+Ca ${ }^{2+}$ system We investigated the role of the $\mathrm{Ca}^{2+}$ ion at molecular level. This approach required prior identification of the putative $\mathrm{Ca}^{2+}$ binding sites on the protein surface. Since the pioneering work of Di Ceva [29], several approaches for predicting $\mathrm{Ca}^{2+}$ binding sites in proteins have been proposed [29-33]. We used a combination of two methods, FEATURE (http://feature.stanford.edu/webfeature) and MetSITE (http://bioinf.cs.ucl.ac.uk/MetSite/MetSite.html) to establish a preliminary consensus score. We used the previously described wild-type APA model as the 3D structure input into the programs [18]. Five possible consensus regions on the APA surface were found presenting the necessary requirements for a satisfactory binding of the calcium ion. As calcium has been previously shown to enhance the affinity of APA for substrates bearing an N-terminal acidic residue [25], we have firstly postulated that the calcium ion would be located in the vicinity of the active site. After visual inspection of the corresponding position of the APA active site on the 3D model of this enzyme [18], the Asp-213 and Asp-218 anchoring points were retained for final placement of the $\mathrm{Ca}^{2+}$ ion. The inhibitor glutamate phosphonate was then docked within the active site according to the position described in our previous papers [18] and the protein+ligand $+\mathrm{Zn}^{2+}+\mathrm{Ca}^{2+}$ system was placed within a $85 \AA$ cubic water box. In order to check the stability of the system, especially the one concerning the chosen $\mathrm{Ca}^{2+}$ placement, several rounds of energy minimisation followed by short molecular dynamics (MD) runs were performed. The molecular mechanics program and the simulation protocol were similar to those used in our previous studies [18]. The refined model of the whole $\mathrm{APA}+\mathrm{GluPO}_{3} \mathrm{H}_{2}+\mathrm{Zn}^{2+}+\mathrm{Ca}^{2+}+$ water system obtained in this way was used in all subsequent calculations. Mutants were obtained solely by changing the side chains of the considered amino acid residues and submitting the corresponding structures to a new cycle of refinement.

Cloning and Site-Directed Mutagenesis - The mouse cDNA encoding APA was used as a template for the generation of mutants by PCR-based site-directed mutagenesis, as previously described [34]. Two overlapping regions of the cDNA were amplified separately, using two flanking oligonucleotides and the two PCR products obtained were used as template for a second round of PCR (see supplemental for details).

The final 2376 bp PCR product was digested with HindIII and EcoRV (New England Biolabs) and the resulting 1505 bp HindIII-EcoRV fragment containing the mutation was used to replace the corresponding non-mutated region (HindIII-EcoRV) of the full-length APA CDNA. The presence of the mutation and the absence of non-specific mutations were confirmed sequencing. 
Cell Culture, Establishment of Stable CHO-K1 Cell Lines Producing Wild-Type and Mutated His-APAs, and Purification of Recombinant His-APAs - CHO-K1 (American Type Culture Collection; Rockeville, MD) cells were maintained in Ham's F12 medium supplemented with $7 \%$ foetal calf serum, $0.5 \mathrm{mM}$ glutamine, $100 \mathrm{units} / \mathrm{ml}$ penicillin and $100 \mu \mathrm{g} / \mathrm{ml}$ streptomycin (all from Invitrogen). Cells were transfected with $1 \mu \mathrm{g}$ of plasmid containing the wild-type or mutated His-APA cDNAs, using Lipofectamine 2000 (Invitrogen), and stable cell lines producing the polyhistidine-tagged wild-type and mutated His-APAs were established as previously described [13]. Stably transfected CHO cells were harvested and a crude membrane preparation obtained, as previously described [13]. Wild-type and mutated HisAPAs were purified from the solubilized crude membrane preparation by metal affinity chromatography with a metal chelate resin column (Talon $\mathrm{Co}^{2+}$ ), as previously described [13]. The purity of the final preparation was assessed by SDS-polyacrylamide gel electrophoresis (PAGE) in 8\% polyacrylamide gels, as described by Laemmli [35]. Proteins were stained with Coomassie Brilliant Blue R-250. Protein concentrations were then determined with the BCA Protein assay kit (Pierce), using bovine serum albumin (BSA) as the standard.

Western Blotting - Purified wild-type and mutated His-APAs were resolved by 8\% SDSPAGE and the proteins were transferred to a PVDF membrane in $25 \mathrm{mM}$ Tris/glycine buffer, pH 8.3 supplemented with $20 \%(\mathrm{~V} / \mathrm{V})$ methanol. His-tagged recombinant proteins were detected with the anti-Xpress antibody (dilution 1:5000), the resulting immune complex was then detected with the ECL plus Western Blotting detection system (GE Healthcare).

Immunofluorescence of Stably Transfected CHO Cells - CHO cells producing wild-type and mutated His-APAs were dispensed (25,000 cells) on coverslips with a diameter of $14 \mathrm{~mm}$. Cells were cultured for $24 \mathrm{~h}$ in Ham's F12 medium in a humidified atmosphere containing 5\% $\mathrm{CO}_{2} / 95 \%$ air. They were then fixed and permeabilized by incubation for $5 \mathrm{~min}$ in $100 \%$ icecold methanol. The cells were rinsed three times in $0.1 \mathrm{M}$ phosphate-buffered saline $\mathrm{pH} 7.4$ (PBS), then saturated by incubation with $5 \%$ BSA for $30 \mathrm{~min}$ at room temperature (RT). They were then incubated with a 1:1000 dilution of rabbit polyclonal anti-(rat APA) serum [36] in $0.5 \%$ BSA in PBS, for $2 \mathrm{~h}$ at room temperature (RT). The coverslips were washed three times with cold PBS and incubated with a 1:1000 dilution of cyanin 3-conjugated polyclonal antirabbit antibody in $0.5 \%$ BSA in PBS for $2 \mathrm{~h}$ at RT. The coverslips were washed three times with PBS and once with water and mounted in Mowiol. Then, cells were examined with a Leica TCS SP II (Leica Microsystems, Heidelberg, Germany) confocal laser scanning microscope equipped with an argon/krypton laser and configured with a Leica DM IRBE inverted microscope. Cyanin 3 fluorescence was detected after 100\% excitation at $568 \mathrm{~nm}$. Images (1024x1024 pixels) were obtained with a 63x magnification oil-immersion objective. Each image corresponded to a cross-section of the cell.

Synthesis of NI926 and NI955 - The previously described pathway for the synthesis of tritiumlabelled RB 151 was a good starting point for the synthesis of inhibitors 6 (NI 926) and 8 (NI 955) [37]. We therefore used this short synthetic approach in order to obtain the desired compounds (Fig. S1).

The esterification of commercially available (S)-N-tertiobutoxycarbonylamino-S-tritylcysteine with trimethylsilyldiazomethane quantitatively yielded compound $\mathbf{1}$ which was then used for the introduction of the carboxylate side chain by a previously described one pot reaction involving a DIBAl-H-induced reduction of the methyl ester moiety leading to an aluminoxyacetal intermediate. The latter intermediate was not isolated and was submitted in situ to a Wittig-Horner reaction leading to compound 2. The $\alpha-\beta$-unsaturated ester 2 was reduced with sodium borohydride in ethanol, the intermediate $\mathbf{3}$ was submitted to a 
saponification reaction affording, the acid 4. Compound 4 was coupled to tbutyl-N-(2aminoethyl)carbamate or glycine tertiobutylester by the $\mathrm{EDCl} / \mathrm{HOBt}$ method, generating the the fully protected inhibitors 5 and $\mathbf{7}$, which were deprotected with trifluoroacetic acid to yield inhibitors 6 (NI 926: (4S)-4-Amino-5-mercapto-N-(2-aminoethyl)-pentanamide) and 8 (NI955: ((4S)-4-amino-5-mercapto-pentanoylamino)-acetic acid), respectively (see supplemental for detail).

\section{Enzyme assay}

Effect of $\mathrm{Ca}^{2+}$ on wild-type and mutated His-APAs activities: Purified wild-type and mutated His-APAs were incubated at $37^{\circ} \mathrm{C}$ with $0.5 \mathrm{mM}$ of a synthetic substrate, GluNA, with various concentrations of $\mathrm{CaCl}_{2}$, in a final volume of $100 \mu \mathrm{l}$ of $50 \mathrm{mM}$ Tris- $\mathrm{HCl}$ buffer $\mathrm{pH}$ 7.4. The sensitivity of wild-type and mutated His-APAs to $\mathrm{CaCl}_{2}$ was determined by establishing dose-dependent activation curves and calculating EC 50 values for $\mathrm{Ca}^{2+}$ activation with Graph Pad Prism 4 software.

Analysis of kinetic parameters: Assays of the activity of wild-type and mutated His-APA enzymes were carried out in $50 \mathrm{mM}$ Tris- $\mathrm{HCl}$ buffer, $\mathrm{pH} 7.4$, with or without $4 \mathrm{mM} \mathrm{CaCl}_{2}$, by monitoring the rate of hydrolysis of GluNA, as previously described [38]. All the assays were performed in black 96-well plates (solid black 96-well, untreated, flat-bottomed plates; Corning Costar). All enzymatic studies were performed in order to remain below $10 \%$ of substrate hydrolysis (initial rate conditions). Progress curves were monitored by following the increase in fluorescence at $460 \mathrm{~nm}\left(\lambda_{\mathrm{ex}}=330 \mathrm{~nm}\right)$, induced by release of the $\beta$-naphthylamine fluorogenic part of the APA substrate. Fluorescence signals were monitored with a photoncounting spectrophotometer (Fusion ${ }^{\mathrm{TM}}$ Universal Microplate Analyzer, Packard) equipped with a temperature-control device and a plate shaker. Kinetic parameters $\left(K_{m}\right.$ and $\left.k_{\text {cat }}\right)$ were determined from Michaelis-Menten plots using EnzFitter software (Biosoft ${ }^{\mathrm{TM}}$ ) with a final concentration of GluNA between $0.005 \mathrm{mM}$ and $2 \mathrm{mM}$ for wild-type enzyme and up to $5 \mathrm{mM}$ for mutated APAs.

Inhibitory potencies of different inhibitors: The sensitivity of wild-type and mutated HisAPAs to inhibition by glutamate-phosphonate $\left(\mathrm{GluPO}_{3} \mathrm{H}_{2}\right)$, glutamate thiol (GluSH), lysine thiol (LysSH), NI926 and NI955 was determined by establishing dose-dependent inhibition curves for a final GluNA concentration of $0.5 \mathrm{mM}$, in the presence of 0 or $4 \mathrm{mM} \mathrm{CaCl}_{2}$ and as these compounds were linear competitive inhibitors, their $\mathrm{Ki}$ were calculated from the formula $\mathrm{Ki}=\mathrm{IC}_{50} /(1+[\mathrm{GluNA}] / \mathrm{Km})$. The concentration of enzymes used ([WT] $=3.9 \times 10^{-}$

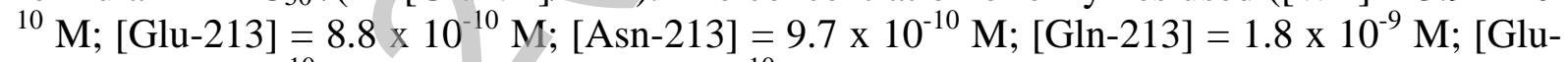
$218]=3.2 \times 10^{-10} \mathrm{M}$; [Ala-218] $=7.3 \times 10^{-10} \mathrm{M}$ ) for this assay were negligible compared to the different Ki.

Statistical analysis - Statistical comparisons were carried out with Student's unpaired $t$ test. Differences were considered significant if $p$ was less than 0.05 . 


\section{RESULTS}

Modelling of APA in the absence of $\mathrm{Ca}^{2+}$ and presence of the APA inhibitor glutamate phosphonate - The 3D model of APA complexed with glutamate phosphonate (Fig. 1A) showed the presence of a hydrophilic pocket containing three residues, two aspartates (Asp213 and Asp-218) and a threonine (Thr-348). The acidic side chain of the inhibitor is pointing towards this pocket and the acidic side chain of Asp-213 is engaged in two hydrogen bonds, one with the $\mathrm{C}^{\alpha}$ amine of Thr-348, and the other with the alcohol side chain of Thr-348. This pocket corresponds to the S1 subsite.

Modelling of APA in the presence of $\mathrm{Ca}^{2+}$ and in the presence of the APA inhibitor glutamate phosphonate - In the the 3D model in absence of $\mathrm{Ca}^{2+}$, the S1 subsite is not sterically hindred by the presence of the inhibitor, allowing for the possible presence of a calcium atom, as previously suggested [25]. We investigated this possibility, by introducing calcium into the 3D model of the APA active site. We used a combination of FEATURE and MetSITE methods to establish a preliminary consensus score. We identified five putative $\mathrm{Ca}^{2+}$ binding sites and selected one that matched our prediction that $\mathrm{Ca}^{2+}$ would bind to the S1 subsite in the vicinity of the acidic side chain of the P1 residue of the substrate/inhibitor. The APA $\mathrm{Ca}^{2+}$ binding site structure obtained in the presence of glutamate phosphonate is presented in Fig. $1 B$. The model showed the presence of one $\mathrm{Ca}^{2+}$ atom in the hydrophilic pocket where it is hexacoordinated with the acidic side chains of Asp-213 and Asp-218, the carbonyl group of Glu-215 and three water molecules (Fig. 1B). One of these water molecules was found to be engaged in a hydrogen bond with the negatively charged carboxylate side chain of glutamate phosphonate. Moreover, the carboxylate side chain of glutamate phosphonate was found to be engaged in another hydrogen bond with the alcohol side chain of Thr-348. Asp-213 also interacted with the nitrogen atom of the $\mathrm{C}^{\alpha}$ amine moiety of Thr-348. Together, these residues constitute the $\mathrm{Ca}^{2+}$ binding site in the APA S1 subsite.

Modelling of Glu-213 and Glu-218 mutated APAs in the presence of $\mathrm{Ca}^{2+}$ and in the presence of the APA inhibitor glutamate phosphonate - (Fig. $1 C$ and $1 D)$. We investigated the role of Asp-213 and Asp-218 in $\mathrm{Ca}^{2+}$ binding by mutating these residues to glutamate residues in the model. When both the Glu-213 (Fig. 1C) and Glu-218 (Fig. 1D) mutations were introduced into the overall APA+glutamate phosphonate $+\mathrm{Zn}^{2+}+\mathrm{Ca}^{2+}+$ water system, the $\mathrm{Ca}^{2+}$ ion appeared to display weak fluctuation around a hexacoordinated position similar to that described above for the wild-type: the ion remained anchored by favourable interactions with the carboxylate moieties of side chains of residues 213 and 218, by the carbonyl group of Glu-215 and by three water molecules. The glutamate phosphonate inhibitor also remained in a position similar to that in the wild-type structure, and established the same interactions with Glu-352, Glu-215, Tyr-471 and the $\mathrm{Zn}^{2+}$ as previously described [18, 21].

Nevertheless, the replacement of aspartic side chains by longer glutamic side chains revealed subtle differences in the behaviour of water/glutamate interactions, depending on which of the 213 or 218 amino-acids are concerned: In the Glu-213 mutant (Fig. 1C), the carbonyl group of glutamate phosphonate interacted with only one water molecule, rather than the three found for wild-type APA (data not shown). The carbonyl group of the inhibitor is rotated in the Glu-218 mutant (Fig. 1D) and interacts with three water molecules, as in wild-type APA. Moreover, when compared to wild-type APA, a modification of the position of the catalytic water molecule was observed in the Glu-213 mutant that appears closer to the Glu-352 and Glu-386 residues.

Site-Directed Mutagenesis, Expression, and Purification of Recombinant wild-type and 
mutated His-APAs - In order to ensure the role of Asp-213 and Asp-218 as Ca ${ }^{2+}$ ligands, we replaced Asp-213 with an alanine, a glutamate, an asparagine, and a glutamine, and Asp-218 with an alanine, an asparagine and a glutamate by site-directed mutagenesis. We also produced a double mutant Asn-213/Asn-218. Constructs encoding wild-type APA and the various mutants were then stably expressed to produce histidine-tagged proteins and the recombinant wild-type or mutated APAs were purified by metal affinity chromatography, as previously described [13]. We first verified if the mutations did not affect the production and processing of the recombinant proteins, by investigating the subcellular distribution of wildtype and mutated His-APAs in stably transfected CHO cells, by immunofluorescence analysis. Confocal microscopy analysis of wild-type and mutated His-APAs showed that all the recombinant enzymes were located at the plasma membrane (Fig. 2A). Western-blot analysis of purified wild-type and mutated His-APAs showed that all recombinant proteins, except for the Ala-213 mutant protein, displayed a major mature form with an apparent molecular weight of $160 \mathrm{kDa}$ and a minor immature form with an apparent molecular weight of $140 \mathrm{kDa}$. In contrast, the Ala-213 mutant displayed a broad diffuse band between 140 and $160 \mathrm{kDa}$ (Fig. 2B), suggesting that during the purification step, the Ala-213 mutant was not stable, avoiding its enzymatic characterization.

Effect of the mutations of the aspartic residues Asp-213 and Asp-218 on $\mathrm{Ca}^{2+}$-mediated activation - As APA activity is dependent on $\mathrm{Ca}^{2+}$ concentration, we determined the $\mathrm{Ca}^{2+}$ activation profile of recombinant wild-type and mutated His-APAs (Fig. $3 A$ and $3 B$ ). $\mathrm{Ca}^{2+}$ (from 0 to $4 \mathrm{mM}$ ) increased the activity of the wild-type enzyme and that of Glu-213 to similar extents, by a factor of 8 to 10 . However Glu-213 activity in the absence of $\mathrm{Ca}^{2+}$ was lower than that of the wild-type enzyme, by a factor of 16. Even in the presence of a supramaximal concentration of $\mathrm{Ca}^{2+}(4 \mathrm{mM})$, Glu-213 activity remained lower than that of the wild-type by a factor of 13.5. The $\mathrm{EC}_{50}$ of $\mathrm{Ca}^{2+}$ for Glu-213 $(590 \mu \mathrm{M})$ was about 10 times higher than that for the wild-type $(49 \mu \mathrm{M})$ (Table 1$)$. In contrast, increasing $\mathrm{Ca}^{2+}$ concentration stimulated Glu-218 activity by a factor of 25, with an $\mathrm{EC}_{50}$ of $212 \mu \mathrm{M}$ (Fig. $3 A$ ). Nevertheless, the activity of these mutants in absence or in presence of $\mathrm{Ca}^{2+}$ was decreased by a factor of 6 and 2 respectively as compared to the corresponding wild-type activities. In contrast, the replacement of Asp-213 and Asp-218 by residues lacking an acidic side chain (Asn-213, Gln-213, and Ala-218 mutants) abolished $\mathrm{Ca}^{2+}$ activation. These mutated enzymes were inhibited by low $\mathrm{Ca}^{2+}$ concentrations superior or equal to $50 \mu \mathrm{M}$ (Fig. $3 B)$.

Enzymatic Activity of Purified Recombinant His-APAs - The enzymatic activities of purified recombinant His-APAs were analysed by determining catalytic constants $\left(K_{m}\right.$ and $\left.k_{\text {cat }}\right)$, in the presence or absence of $4 \mathrm{mM} \mathrm{Ca}^{2+}$, using GluNA as a substrate (Table 2). In the absence of $\mathrm{Ca}^{2+}$, the replacement of Asp-213 or Asp-218 by a glutamate residue led to a significant decrease in substrate hydrolysis. Kinetic studies showed, for Glu-213, that this difference was due to an increase in $K_{m}$ (by a factor of 5.2) and a decrease in $k_{\text {cat }}$ (by a factor of 1.9) resulting in a 10-fold decrease in the $k_{c a t} / K_{m}$ ratio. Similarly, the decrease in substrate hydrolysis for Glu-218 was due to an increase in $K_{m}$ (by a factor of 2) and a decrease in $k_{\text {cat }}$ (by a factor of 1.9) resulting in the $k_{c a t} / K_{m}$ ratio decreasing by a factor of 3.7. The addition of $4 \mathrm{mM} \mathrm{Ca}^{2+}$ led to 7.5 times higher levels of substrate hydrolysis by wild-type APA, mainly due to $K_{m}$ decreasing by a factor of 10 . In the presence of $4 \mathrm{mM} \mathrm{Ca}^{2+}$, the Glu-213 mutant displayed significantly lower levels of GluNA hydrolysis than the wild-type enzyme. The $K_{m}$ value of Glu-213 was 31 times higher than that of wild-type APA, and the corresponding $k_{\text {cat }}$ value was 3 times higher than that of wild-type APA. This resulted in $k_{c a t} / K_{m}$ ratio lower than that of the wild-type APA by a factor of 10 . In the presence of $4 \mathrm{mM} \mathrm{Ca}^{2+}$, the Glu-218 mutant 
displayed only slightly lower levels of GluNA hydrolysis than wild-type APA, resulting in a decrease in $k_{c a t} / K_{m}$ ratio by a factor of 1.2 . The $K_{m}$ and $k_{c a t}$ values were slightly higher (1.6 times higher and 1.9 times higher, respectively) than those for wild-type APA. The presence of $\mathrm{Ca}^{2+}$ increased GluNA hydrolysis by a factor of 7.4 for the Glu-213 mutant and 24 for the Glu-218 mutant.

However, in the presence or absence of $\mathrm{Ca}^{2+}$, the Asn-213, Gln-213 and Ala-218 showed a decreased GluNA hydrolysis efficiency, mostly due to an increase of the $K_{m}$ value. In the absence of $\mathrm{Ca}^{2+}, k_{c a t} / K_{m}$ ratios of Asn-213, Glu-213 and Ala-218 were lower than that for the wild-type enzyme by factors of 2.5, 1.5 and 22, respectively. In the presence of $\mathrm{Ca}^{2+}$, the $k_{c a t} / K_{m}$ ratios for Asn-213, Gln-213 and Ala-218 were much lower than that for the wild-type, by factors of 40, 36 and 511, respectively. Moreover, the introduction of $\mathrm{Ca}^{2+}$ did not enhance activity, instead decreasing GluNA hydrolysis efficiency by a factor of 2, 3 and 3 for Asn213, Gln-213 and Ala-218 respectively. The mutants Asn-218 and Asn-213/Asn-218 did not display any activity.

Inhibitory Potencies of Various Classes of Compounds on Purified Recombinant His-APAs We further characterized the role of the Asp-213 and Asp-218 residues of APA, by evaluating the inhibitory potencies of various classes of compounds (with acidic or basic side chains) on GluNA $(0.5 \mathrm{mM})$ hydrolysis by the wild-type and mutated enzymes in the absence or in the presence of $\mathrm{Ca}^{2+}(4 \mathrm{mM})$. The results are summarized in Figures 4 and 5 . $\mathrm{GluPO}_{3} \mathrm{H}_{2}$, a pseudoanalogue of the transition state, was 6-fold and 3-fold less potent towards Glu-213 and Glu-218 than towards the wild-type enzyme $(\mathrm{Ki}=1.75 \mu \mathrm{M})$ in the absence of $\mathrm{Ca}^{2+}$. In the presence of $\mathrm{Ca}^{2+}$, the inhibitory potency of $\mathrm{GluPO}_{3} \mathrm{H}_{2} \mathrm{was} 22$ times higher for the wild-type $(\mathrm{Ki}=0.08 \mu \mathrm{M}), 19$ times higher for Glu-213 $(\mathrm{Ki}=0.59 \mu \mathrm{M})$ and 39 times higher for Glu-218 $(\mathrm{Ki}=0.15 \mu \mathrm{M})$. In the absence of $\mathrm{Ca}^{2+}$, GluSH inhibited equally wild-type APA, Glu-213, Asn-213, Gln-213 and Glu-218 $(\mathrm{Ki}=1.2 \mu \mathrm{M}, 1.14 \mu \mathrm{M}, 2.11 \mu \mathrm{M}, 1.3 \mu \mathrm{M}$ and $1.82 \mu \mathrm{M}$, respectively) and is weaker on Ala-218 $(\mathrm{Ki}=4.3 \mu \mathrm{M})$. The introduction of $\mathrm{Ca}^{2+}$ enhanced GluSH inhibitory potency on wild-type, Glu-213 and Glu-218 by a factor 9.2, 2.5 and 2.7 respectively ( $\mathrm{Ki}=0.13 \mu \mathrm{M}, 0.45 \mu \mathrm{M}$ and $0.66 \mu \mathrm{M}$, respectively). LysSH, a basic side chain inhibitor, inhibited Glu-213 and Glu-218 less strongly than wild-type APA (Ki $=0.26 \mu \mathrm{M})$, by factors of 10 and 3 , in the absence of $\mathrm{Ca}^{2+}$. The addition of $\mathrm{Ca}^{2+}$ decreased the inhibitory potency of LysSH by a factor of 12 for wild-type APA $(\mathrm{Ki}=3.15 \mu \mathrm{M})$, by a factor of 7.5 for Glu-213 $(\mathrm{Ki}=20.74 \mu \mathrm{M})$ and by a factor of 3 for Glu-218 $(\mathrm{Ki}=2.7 \mu \mathrm{M})$. We then investigated the binding of LysSH on Asn-213, Gln-213 and Ala-218 mutants in the absence of $\mathrm{Ca}^{2+}$ and we found that the inhibitory potency of this inhibitor was lower for these mutants than for the wild-type enzyme, by factors of 48, 166 and 6.3.

Design and Characterization of new APA inhibitors - For accurate exploration of the organisation of the S1 subsite, we designed, based on the 3D model, and synthesized, using GluSH as a template, two new inhibitors NI926 and NI955. Amidification of the carboxylic side chain of GluSH by a diaminoethyl side chain generated NI926, an inhibitor bearing a free amine side chain that may interact with the carboxylic side chain of Asp-218. To challenge this interaction, we synthesized the carboxylic acid NI955, by carrying out the amidification of the carboxylic side chain of GluSH with glycine. These two compounds are similar in terms of chain length but have opposite charges.

In the absence of $\mathrm{Ca}^{2+}$, NI926 was a highly potent inhibitor of wild-type APA, with a Ki of $70 \mathrm{nM}$. Its inhibitory potency for Glu-213, Asn-213 and Gln-213 was lower than that for the wild-type, by factors of 16, 61 and 201, respectively. Moreover, NI926 inhibited (factor of 1.5) wild-type APA and Glu-218 similarly, but was less potent (by a factor of 33) with Ala218. The introduction of $\mathrm{Ca}^{2+}$ reduced the potential of NI926 to inhibit the wild-type, Glu-213 
and Glu-218 (by a factor of 16, 11 and 6, respectively) but the inhibition profile was similar to that observed in the absence of $\mathrm{Ca}^{2+}$ (NI926 inhibits wild-type APA 11 times more strongly than Glu-213 and 2 times more strongly than Glu-218). In the absence of $\mathrm{Ca}^{2+}$, NI955 had the same inhibitory potency towards wild-type APA, Glu-213 and Asn-213. In contrast, this compound inhibited better wild-type APA than Gln-213 and Glu-218 by a factor of 5 and 3 respectively. Interestingly, in the absence of $\mathrm{Ca}^{2+}$, NI955, was 29-fold more potent on Ala218 than on wild-type APA. $\mathrm{Ca}^{2+}$ increased the inhibitory potency of NI955 against wild-type and Glu-218 enzymes by factors of two and 8.5, respectively, but had no effect on inhibitory potency against Glu-213. 


\section{DISCUSSION}

APA belongs to the monozinc aminopeptidase family, the members of which require $\mathrm{Zn}^{2+}$ for catalytic activity. The activity of APA, unlike that of other monozinc aminopeptidases, is enhanced by $\mathrm{Ca}^{2+}$ [26]. In this study, we identified the S1 subsite in APA and demonstrated the presence, within this subsite, of a single $\mathrm{Ca}^{2+}$ atom. This led us to characterize the mode of $\mathrm{Ca}^{2+}$ coordination and the interaction of this ion with the side chain carboxylate of the acidic $\mathrm{P} 1$ residue of the substrate, accounting for the specificity of APA for substrates with $\mathrm{N}$ terminal acidic residues in the presence of $\mathrm{Ca}^{2+}$.

We previously generated and validated a 3D model of the mouse APA ectodomain [18]. In order to identify the S1 subsite, we docked the APA inhibitor glutamate phosphonate into the APA active site, in the absence of $\mathrm{Ca}^{2+}$. We observed that the acidic lateral chain of the P1 residue of this inhibitor projected into a pocket formed by the three main residues of the S1 subsite, Asp-213, Asp-218 and Thr-348.

When glutamate phosphonate was docked in the APA active site 3D model, in presence of $\mathrm{Ca}^{2+}$, a site favorable for chelation was identified within the S1 subsite, in the vicinity of the acidic side chain of glutamate phosphonate. This cation was hexacoordinated to the carboxylate groups of the Asp-213 and Asp-218 side chains, the $C^{\alpha}$ carbonyl group of Glu215 and three water molecules. One of these water molecules established a hydrogen bond with the carboxylate side chain of glutamate phosphonate. The presence of $\mathrm{Ca}^{2+}$ in the $\mathrm{S} 1$ subsite led to reorganization of the S1 subsite, with a shift in the orientation of the Asp-213 and Asp-218 side chains towards $\mathrm{Ca}^{2+}$. As these interactions were visualized in a 3D model of APA generated purely by modeling, rather than based on the crystal structure of APA, their validation by site-directed mutagenesis in structure-function studies is essential.

We first assessed the involvement of Asp-213 and Asp-218 in $\mathrm{Ca}^{2+}$ binding, by replacing these residues by site-directed mutagenesis. Confocal microscopy analysis showed that all recombinant APAs were similarly expressed at the plasma membrane, consistent with the correct processing of wild-type and mutated APAs. Western-blot analysis of purified recombinant APAs showed that all wild-type and mutated APAs, with the exception of the Ala-213 mutant, had an apparent molecular mass of $160 \mathrm{kDa}$, corresponding to the mature glycosylated APA, as previously reported $[13,19]$. By contrast, the Ala-213 mutant displayed a broad diffuse band between 140 and $160 \mathrm{kDa}$, indicating that this protein, despite being correctly expressed at the plasma membrane, was not stable during the purification process. Consistent with this observation, the corresponding purified enzyme was inactive.

We then investigated the activation of wild-type and mutated APAs by $\mathrm{Ca}^{2+}$. We observed, as previously described [13], that wild-type APA was strongly activated by $\mathrm{Ca}^{2+}$, with enzymatic activity increasing by a factor of $8 \mathrm{as} \mathrm{Ca}^{2+}$ concentration increased from 0 to $4 \mathrm{mM}$. The replacement of Asp-213 and Asp-218 by glutamate residues (Glu-213 and Glu-218), conserving the negative charge, maintained the ability of these enzymes to be activated by $\mathrm{Ca}^{2+}$, but their maximal activities remained consistently below that of the wild type. However, Glu-213 and Glu-218 were less sensitive to $\mathrm{Ca}^{2+}$ than the wild-type enzyme. By contrast, the replacement of Asp-213 or Asp-218 by non acidic residues (Asn-213, Gln-213 and Ala-218) devoid of negative charges reduced enzyme activity in the absence of $\mathrm{Ca}^{2+}$ and abolished activation by $\mathrm{Ca}^{2+}$. Thus, Asp-213 and Asp-218 play a critical role in the activity of APA, with the negative charges and side-chain lengths of these residues crucial for $\mathrm{Ca}^{2+}$ activation. Furthermore, the prevention of $\mathrm{Ca}^{2+}$ activation by a single mutation affecting either of these residues demonstrates that that both Asp-213 and Asp-218 are required for $\mathrm{Ca}^{2+}$ binding. 
We determined the kinetic parameters for mutated enzymes in the presence and absence of $\mathrm{Ca}^{2+}$. As previously reported $[13,26]$, we showed that the addition of $\mathrm{Ca}^{2+}$ enhanced wildtype APA activity by increasing affinity for the substrate GluNA (by a factor of 10) without significantly modifying substrate hydrolysis velocity $\left(k_{c a t}\right)$, increasing cleavage efficiency by a factor of 8. By contrast, greater cleavage efficiency of the Glu-213 enzyme in the presence of $4 \mathrm{mM} \mathrm{Ca}^{2+}$ resulted mostly from an increase in $k_{c a}$, with only a slight increase in affinity for GluNA. This difference in $\mathrm{Ca}^{2+}$ activation for Glu-213 and wild-type APA may be correlated with the shift of the catalytic water molecule toward the residues involved in its polarization - Glu-386 and Glu-352 - as observed in the 3D model of the Glu-213 active site in the presence of $\mathrm{Ca}^{2+}$. As observed for wild-type APA, the addition of $\mathrm{Ca}^{2+}$ increased the cleavage efficiency of Glu-218 by strongly increasing its affinity for the substrate, thereby restoring the cleavage efficiency of the mutated enzyme to levels close to those of the wildtype enzyme. If the negative charges on residues 213 and 218 were abolished, as in the Asn213, Gln-213, Asn-218, Ala-218 and Asn-213/Asn-218 mutants, the addition of $\mathrm{Ca}^{2+}$ did not increase cleavage efficiency, and even resulted in inhibition in some cases. These data demonstrate the involvement of both Asp-213 and Asp-218 in $\mathrm{Ca}^{2+}$ binding, and highlight the role of these residues in S1 subsite organization and enzymatic activity. The crucial role of the Asp-213 residue in $\mathrm{Ca}^{2+}$ binding is consistent with a recent study by Goto et al. [39] showing that, in human APA, the corresponding aspartate, Asp-221, is involved in the modulation of APA activity by $\mathrm{Ca}^{2+}$.

$\mathrm{Ca}^{2+}$ affected the affinity of APA for both acidic and basic substrates. We therefore evaluated the effects of the $\mathrm{Ca}^{2+}$-induced modulation of APA activity, by measuring the inhibitory potency of various inhibitors in the presence and absence of $\mathrm{Ca}^{2+}$. All the inhibitors studied interact with the S1 subsite, but differ in the nature of their zinc-chelating group and the nature of the P1 side chain: (i) the pseudoanalog of the transition state, $\mathrm{GluPO}_{3} \mathrm{H}_{2}$ [40], which interacts with the amine binding site, the $\mathrm{S} 1$ subsite, the Tyr-471 residue involved in transition state stabilization, and the zinc ion, via its phosphoryl oxygens or (ii) the two ß-amino thiol inhibitors, GluSH [41] and LysSH [42], which interact with the amine binding site, the S1 subsite, via their acidic or basic side chains, and the zinc ion, via their chelating thiol group.

As inhibitors may differ in terms of their P1 side chains, we hypothesized that the difference between the Ki values of mutated APAs and wild-type APA reflected changes in the docking of the $\mathrm{P} 1$ residue into the $\mathrm{S} 1$ subsite.

In the absence of $\mathrm{Ca}^{2+}$, wild-type APA had an affinity for inhibitors resembling basic residues (such as LysSH) five times greater than that for inhibitors resembling acidic residues (such as GluSH). If Asp-218 was substituted by a glutamate or an alanine in the absence of $\mathrm{Ca}^{2+}$, this ratio was slightly different from that for the wild-type APA. Thus, in the absence of $\mathrm{Ca}^{2+}$, Asp-218 did not interact with the basic or acidic side chain of these inhibitors. By contrast, in the absence of $\mathrm{Ca}^{2+}$, the ratio for Glu-213

was lower than that for the wild-type enzyme. Similarly, the Asn-213 and Gln-213 enzymes had higher affinities for inhibitors resembling acidic residues (such as GluSH) than for inhibitors resembling basic residues (such as $\mathrm{LysSH}$ ). Thus, in the absence of $\mathrm{Ca}^{2+}$, $\mathrm{LysSH}$ interacts with the negative charge of Asp-213 in wild-type APA, and the length of the side chain of the acidic residue in position 213 is important for this interaction. This validates the 3D model of APA, in which the Asp-213 residue was found to be located at the entrance to the $\mathrm{S} 1$ subsite. 
The presence of $\mathrm{Ca}^{2+}$ rendered wild-type APA strictly specific for inhibitors with an acidic side chain, as previously shown [13]. This is illustrated by the 24 times greater inhibition of wild-type APA obtained with GluSH than with LysSH in the presence of $\mathrm{Ca}^{2+}$. In the presence of $\mathrm{Ca}^{2+}$, we observed an increase in the affinity of the mutated enzymes, Glu-213 and Glu-218, for inhibitors resembling acidic residues and a decrease in the affinity of these enzymes for inhibitors resembling basic residues, as reported for the wild-type enzyme. However, the inhibitor specificity of mutated enzymes nevertheless remained less strict than that of wild-type APA, particularly for the Glu-218 enzyme. This may result from the position of the Glu-218 acidic side chain closer to the ammonium group of LysSH than that of the acidic side chain of Asp-218 in wild-type APA, allowing Glu-218 to establish a favorable electrostatic interaction with this inhibitor, as suggested from the 3D model of the active site of this mutated enzyme. This hypothesis is consistent with the ability of Glu-213 and Glu-218 to bind $\mathrm{Ca}^{2+}$, but with lower levels of activation observed than for the wild-type enzyme, as shown by the analysis of kinetic parameters and structural data.

To refine the position of Asp-218 in the S1 subsite, we then designed new pharmacological tools, NI926 and NI955, on the basis of the 3D model of wild-type APA. Both these inhibitors are $ß$-amino thiol inhibitors, in which the side chain of the P1 residue is longer than that of lysine thiol. The side chain of NI926 is basic, whereas that of NI955 is acidic. In the absence of $\mathrm{Ca}^{2+}$, NI926 had an inhibitory potency for wild-type APA of $70 \mathrm{nM}$. This inhibitor is the best APA inhibitor known to date in the absence of $\mathrm{Ca}^{2+}$. It was less potent with Ala-218 than with Glu-218 and wild-type APA, suggesting that the negative charge of Asp-218 is required for binding of the basic side chain of NI926 in the S1 subsite. By contrast, in the absence of $\mathrm{Ca}^{2+}$, NI955 was less potent against the wild-type and Glu-218 enzymes than against Ala-218. Thus, in the absence of $\mathrm{Ca}^{2+}$, the negative charges on the side chain of Asp-218 and the anionic carboxylate moiety of NI955 have a repulsive electrostatic effect, pushing NI955 out of the S1 subsite. This finding both shows the Asp-218 residue to be located towards the bottom of the S1 subsite and validates the 3D model of wild-type APA.

In conclusion, this study highlights the role of Asp-213 and Asp-218 in $\mathrm{Ca}^{2+}$ binding and, therefore, in $\mathrm{Ca}^{2+}$-induced APA substrate specificity. Our data provide new insight into the organization of the APA active site, delineating the S1 subsite, precisely localizing Asp-213 and Asp-218 within this subsite and identifying the mode of interaction of these residues with the $\mathrm{Ca}^{2+}$ ion and that of the $\mathrm{Ca}^{2+}$ ion with the acidic side chain of the substrate. The role we have demonstrated for the Asp-213 and Asp-218 residues is consistent with the 3D model of APA, thus validating this model. Moreover, we have shown here the interest to have developed the APA 3D model for the design of new potent APA inhibitors, such as NI926. This model provides new insight into the organization of the $\mathrm{S} 1$ subsite and $\mathrm{Ca}^{2+}$ binding and will be a useful tool for designing an inhibitor pharmacophore, which may lead to the development of a new generation of APA inhibitors functioning as central-acting antihypertensive agents. 


\section{Acknowledgments}

We thank Dr. S. Wilk and Dr. D. Healy for providing the APA antiserum, Dr. B. Lejczak for the gift of the inhibitor glutamate phosphonate and Dr. I. Banegas for her help to performed some experiments. This research was supported by grant from the Fondation pour la recherche Medicale, by the Institut National de la Santé et de la Recherche Medicale and the Centre National de la Recherche Scientifique institutes.

\section{References}

1 Nagatsu, I., Nagatsu, T., Yamamoto, T., Glenner, G. G. and Mehl, J. W. (1970) Purification of aminopeptidase A in human serum and degradation of angiotensin II by the purified enzyme. Biochim. Biophys.. 198, 255-270.

2 Wilk, S. and Healy, D. (1993) Glutamyl aminopeptidase (aminopeptidase A), the BP1/6C3 antigen. Adv. in Neuroimmunol. 3, 195-207

3 Lodja, Z. and Gossrau, R. (1980) Study on aminopeptidase A. Histochemistry 67, 267290

4 Zini, S., Masdehors, P., Lenkei, Z., Fournie-Zaluski, M. C., Roques, B. P., Corvol, P. and Llorens-Cortes, C. (1997) Aminopeptidase A: distribution in rat brain nuclei and increased activity in spontaneously hypertensive rats. Neuroscience 78, 1187-1193. Chauvel, E. N., Llorens-Cortès, C., Coric, P., Wilk, S., Roques, B. and FourniéZaluski, M. C. (1994b) Differential inhibition of Aminopeptidase A and Aminopeptidase N by new $\beta$-amino thiols. J. Med. Chem. 37, 2950-2956

6 Zini, S., Fournie-Zaluski, M. C., Chauvel, E., Roques, B. P., Corvol, P. and LlorensCortes, C. (1996) Identification of metabolic pathways of brain angiotensin II and III using specific aminopeptidase inhibitors: predominant role of angiotensin III in the control of vasopressin release. Proc. Natl. Acad. Sci. U S A 93, 11968-11973.

7 Fournie-Zaluski, M. C., Fassot, C., Valentin, B., Djordjijevic, D., Reaux-Le Goazigo, A., Corvol, P., Roques, B. P. and Llorens-Cortes, C. (2004) Brain renin-angiotensin system blockade by systemically active aminopeptidase A inhibitors: a potential treatment of salt-dependent hypertension. Proc. Natl. Acad. Sci. U S A 101, 77757780

8 Reaux, A., Fournie-Zaluski, M. C., David, C., Zini, S., Roques, B. P., Corvol, P. and Llorens-Cortes, C. (1999) Aminopeptidase A inhibitors as potential central antihypertensive agents. Proc. Natl. Acad. Sci. U S A 96, 13415-13420

9 Iturrioz, X., Reaux-Le Goazigo, A. and Llorens-Cortes, C. (2004) Aminopeptidase Inhibitor as Anti-Hypertensive Drugs. Kluwer Academic/Plenum Publishers

10 Reaux, A., Iturrioz, X., Vazeux, G., Fournie-Zaluski, M. C., David, C., Roques, B. P., Corvol, P. and Liorens-Cortes, C. (2000) Aminopeptidase A, which generates one of the main effector peptides of the brain renin-angiotensin system, angiotensin III, has a key role in central control of arterial blood pressure. Biochem. Soc. Trans. 28, 435440

11 Thunnissen, M. M., Nordlund, P. and Haeggstrom, J. Z. (2001) Crystal structure of human leukotriene A(4) hydrolase, a bifunctional enzyme in inflammation. Nat. Struct. Biol. 8, 131-135.

12 Iturrioz, X., Rozenfeld, R., Michaud, A., Corvol, P. and Llorens-Cortes, C. (2001) Study of asparagine 353 in aminopeptidase A: characterization of a novel motif (GXMEN) implicated in exopeptidase specificity of monozinc aminopeptidases. Biochemistry 40, 14440-14448 
13 Iturrioz, X., Vazeux, G., Celerier, J., Corvol, P. and Llorens-Cortes, C. (2000) Histidine 450 plays a critical role in catalysis and, with $\mathrm{Ca} 2+$, contributes to the substrate specificity of aminopeptidase A. Biochemistry 39, 3061-3068

14 Vazeux, G., Iturrioz, X., Corvol, P. and Llorens-Cortes, C. (1997) A tyrosine residue essential for catalytic activity in aminopeptidase A. Biochem. J. 327, 883-889

15 Vazeux, G., Iturrioz, X., Corvol, P. and Llorens-Cortes, C. (1998) A glutamate residue contributes to the exopeptidase specificity in aminopeptidase A. Biochem. J. 334, 407413

16 Vazeux, G., Wang, J., Corvol, P. and Llorens-Cortes, C. (1996) Identification of glutamate residues essential for catalytic activity and zinc coordination in aminopeptidase A. J. Biol. Chem. 271, 9069-9074.

17 Wang, J. Y. and Cooper, M. D. (1993) A histidine residue in the zinc-binding motif of aminopeptidase A is critical for enzymatic activity. Proc. Natl. Acad. Sci. USA 90, 1222-1226

18 Rozenfeld, R., Iturrioz, X., Maigret, B. and Llorens-Cortes, C. (2002) Contribution of molecular modeling and site-directed mutagenesis to the identification of two structural residues, Arg-220 and Asp-227, in aminopeptidase A. J. Biol. Chem. 277, 29242-29252

19 Rozenfeld, R., Muller, L., El Messari, S. and Llorens-Cortes, C. (2004) The Cterminal domain of aminopeptidase $\mathrm{A}$ is an intramolecular chaperone required for the correct folding, cell surface expression, and activity of this monozinc aminopeptidase. J. Biol. Chem. 279, 43285-43295

20 Lejczak, B., De Choszczak, M. P. and Kafarski, P. (1993) Inhibition of aminopeptidases by phosphonic acid and phosphinic acid analogues of aspartic and glutamic acids. J. Enzyme. Inhib. 7, 97-103

21 Rozenfeld, R., Iturrioz, X., Okada, M., Maigret, B. and Llorens-Cortes, C. (2003) Contribution of molecular modeling and site-directed mutagenesis to the identification of a new residue, glutamate 215 , involved in the exopeptidase specificity of aminopeptidase A. Biochemistry 42, 14785-14793

22 Addlagatta, A., Gay, L. and Matthews, B. W. (2006) Structure of aminopeptidase N from Escherichia coli suggests a compartmentalized, gated active site. Proc. Natl. Acad. Sci. U S A 103, 13339-13344.

23 Ito, K., Nakajima, Y., Onohara, Y., Takeo, M., Nakashima, K., Matsubara, F., Ito, T. and Yoshimoto, T. (2006) Crystal structure of aminopeptidase N (proteobacteria alanyl aminopeptidase) from Escherichia coli and conformational change of methionine 260 involved in substrate recognition. J. Biol. Chem. 281, 33664-33676

24 Onohara, Y., Nakajima, Y., Ito, K., Xu, Y., Nakashima, K., Ito, T. and Yoshimoto, T. (2006) Crystallization and preliminary X-ray characterization of aminopeptidase $\mathrm{N}$ from Escherichia coli. Acta. Crystallogr. Sect. F Struct. Biol. Cryst. Commun. 62, 699-701

25 Danielsen, E. M., Noren, O., Sjostrom, H., Ingram, J. and Kenny, A. J. (1980) Proteins of the kidney microvillar membrane. Aspartate aminopeptidase: purification by immunoadsorbent chromatography and properties of the detergent- and proteinasesolubilized forms. Biochem. J. 189, 591-603.

26 Glenner, G. G., Mc, M. P. and Folk, J. E. (1962) A mammalian peptidase specific for the hydrolysis of N-terminal alpha-L-glutamyl and aspartyl residues. Nature 194, 867

27 Yamada, R., Mizutani, S., Kurauchi, O., Okano, K., Imaizumi, H., Narita, O. and Tomoda, Y. (1988) Purification and characterization of human placental aminopeptidase A. Enzyme 40, 223-230 
28 Feracci, H., Benajiba, A., Gorvel, J. P., Doumeng, C. and Maroux, S. (1981) Enzymatic and immunological properties of the protease form of aminopeptidase $\mathrm{N}$ and A from pig and rabbit intestinal brush border. Biochim. Biophys. Acta. 658, 148157

29 Nayal, M. and Di Cera, E. (1994) Predicting Ca(2+)-binding sites in proteins. Proc. Natl. Acad. Sci. U S A 91, 817-821

30 Deng, H., Chen, G., Yang, W. and Yang, J. J. (2006) Predicting calcium-binding sites in proteins - a graph theory and geometry approach. Proteins 64, 34-42

31 Liang, M. P., Banatao, D. R., Klein, T. E., Brutlag, D. L. and Altman, R. B. (2003) WebFEATURE: An interactive web tool for identifying and visualizing functional sites on macromolecular structures. Nucleic. Acids. Res. 31, 3324-3327

32 Sodhi, J. S., Bryson, K., McGuffin, L. J., Ward, J. J., Wernisch, L. and Jones, D. T. (2004) Predicting metal-binding site residues in low-resolution structural models. J. Mol. Bio.l 342, 307-320

33 Yang, W., Lee, H. W., Hellinga, H. and Yang, J. J. (2002) Structural analysis, identification, and design of calcium-binding sites in proteins. Proteins 47, 344-356

34 Herlitze, S. and Koenen, M. (1990) A general and rapid mutagenesis method using polymerase chain reaction. Gene 91, 143-147

35 Laemmli, U. K. (1970) Cleavage of structural proteins during the assembly of the head of bacteriophage T4. Nature 227, 680-685

36 Song, L., Ye, M., Troyanovskaya, M., Wilk, E., Wilk, S. and Healy, D. P. (1994) Rat kidney glutamyl aminopeptidase (aminopeptidase A); molecular identity and cellular localization. Am. J. Physiol. 267, F546-557.

37 Inguimbert, N., Coric, P., Dhotel, P., Llorens-Cortes, C., Fournie-Zaluski, M. C. and Roques, B. P. (2004) Synthesis and separation of tritiated inhibitors of aminopeptidase A and their prodrugs. J. Label. Compd. Radiopharm. 47, 1-9

38 Chauvel, E. N., Coric, P., Llorens-Cortes, C., Wilk, S., Roques, B. P. and FournieZaluski, M. C. (1994) Investigation of the active site of aminopeptidase A using a series of new thiol-containing inhibitors. J. Med. Chem. 37, 1339-1346

39 Goto, Y., Hattori, A., Mizutani, S. and Tsujimoto, M. (2007) Asparatic acid 221 is critical in the calcium-induced modulation of the enzymatic activity of human aminopeptidase A. J. Biol. Chem. 282, 37074-37081

40 Lejczak, B., Kafarski, P. and Zygmunt, J. (1989) Inhibition of aminopeptidases by aminophosphonates. Biochemistry 28, 3549-3555

41 Wilk, S. and Thurston, L. S. (1990) Inhibition of angiotensin III formation by thiol derivatives of acidic amino acids. Neuropeptides 16, 163-168

42 Ocain, T. D. and Rich, D. H. (1987) L-lysinethiol: a subnanomolar inhibitor of aminopeptidase B. Biochem. Biophys. Res. Commun. 145, 1038-1042. 


\section{Figure Legends}

Fig. 1. Organization of the S1 subsite of wild-type, Glu-213 and Glu-218 APAs.

The 3D model of wild-type APA active site complexed with the inhibitor glutamate phosphonate (in orange) without (A) or with calcium (B) revealed a hydrophilic pocket corresponding to the S1 subsite (amino acids in green). The 3D model of the Glu-213 (C) and Glu-218 (D) APA active site complexed with the inhibitor glutamate phosphonate (in orange) with calcium.

Fig. 2. Expression of histidine-tagged wild-type and mutated mouse recombinant APAs. (A) Transfected CHO cells stably expressing wild-type and mutated His ${ }_{6}$-APAs were fixed and immunolabelled with a rabbit polyclonal anti-(rat-APA) serum, which was detected with a cyanin 3-conjugated anti-rabbit antibody. Immunofluorescence was observed by confocal microscopy. The bar represents $20 \mu \mathrm{m}$. (B) Crude membrane preparations were solubilized and subjected to metal affinity chromatography, as previously described [13]. Material eluted from the column was analyzed by SDS-PAGE and Western blot analysis using a mouse anti$\mathrm{X}$-press antibody and an anti-mouse coupled HRP antibody. Immune complexes were resolved by chemiluminescence.

Fig. $3 A$ and $3 B$. Effect of the divalent cation $\mathrm{Ca}^{2+}$ on wild-type, Asp-213 and Asp-218 mutated APAs activities.

Purified wild-type (0.06 $\mu \mathrm{g})$, Asp-213 mutated APAs (Glu-213: $0.06 \mu \mathrm{g}$, Asn-213: $0.3 \mu \mathrm{g}$, Gln-213: $1.2 \mu \mathrm{g}$ ) and Asp-218 mutated APAs (Ala-218:1.2 $\mu \mathrm{g}$, Glu-218: $0.06 \mu \mathrm{g}$ ) were incubated at $37{ }^{\circ} \mathrm{C}$ for $30 \mathrm{~min}$ in the presence of $0.5 \mathrm{mM}$ GluNA, with increasing concentrations of calcium (from 0 to $4 \mathrm{mM}$ ).

Fig. 4. Ki values $(\mu \mathrm{M})$ for $\mathrm{GluPO}_{3} \mathrm{H}_{2}$, GluSH and $\mathrm{LysSH}$ inhibitors with wild-type and mutated recombinant APAs.

$\mathrm{Ki}$ values are the means \pm the standard error of the mean of three to nine experiments with duplicate determinations. ${ }^{*}, p<0.05,{ }^{* *}, p<0.01,{ }^{* * *}, p<0.001$, ns, no significant when compared to the corresponding wild-type values. -, not measurable.

Fig. 5. Ki values ( $\mu M$ ) for NI926 and NI955 inhibitors with wild-type and mutated recombinant APAs.

Ki values are the means \pm the standard error of the mean of three to eight experiments with duplicate determinations. ${ }^{*}, p<0.05,{ }^{* *}, p<0.01,{ }^{* * *}, p<0.001$, ns, no significant when compared to the corresponding wild-type values. -, not measurable. 


\section{Tables}

Table 1. EC 50 for calcium activation of wild-type and mutated His-APAs

\begin{tabular}{c|c}
\hline Enzyme & EC50 $(\mu \mathrm{M})$ \\
\hline Wild-type & $\mathbf{4 9 \pm 4}$ \\
Asn-213 & no activation \\
Glu-213 & $\mathbf{5 9 0} \pm \mathbf{1 5}$ \\
Gln-213 & no activation \\
Ala-218 & no activation \\
Glu-218 & $\mathbf{2 1 2} \pm \mathbf{3 0}$ \\
& \\
\hline
\end{tabular}

Values are mean \pm SEM from three separate experiments with duplicate determination.

Table 2. Kinetic parameters for wild-type and mutated His APAs in absence or in presence of $4 \mathbf{m M}$ $\mathrm{Ca}^{2+}$

\begin{tabular}{|c|c|c|c|c|c|c|}
\hline \multirow{2}{*}{ Enzyme } & $\begin{array}{c}K_{m} \\
(\mu \mathrm{M})\end{array}$ & $k_{c a t}$ & $\begin{array}{c}k_{c a t} / K_{m} \\
\left(\mathrm{mM}^{-1} \cdot \mathrm{s}^{-1}\right)\end{array}$ & $\begin{array}{c}K_{m} \\
(\mu \mathrm{M})\end{array}$ & $\begin{array}{l}k_{c a t} \\
\left(\mathrm{~s}^{-1}\right)\end{array}$ & $\begin{array}{c}k_{c a t} / K_{m} \\
\left(\mathrm{mM}^{-1} \cdot \mathrm{s}^{-1}\right)\end{array}$ \\
\hline & & & & \multicolumn{3}{|c|}{$4 \mathrm{mM} \mathrm{Ca}^{2+}$} \\
\hline Wild-type & $1475 \pm 34$ & $295 \pm 12$ & 200 & $152 \pm 10$ & $232 \pm 9$ & 1526 \\
\hline Glu-213 & $7686 \pm 877$ & $162 \pm 24$ & $21^{*}$ & $4618 \pm 711$ & $720 \pm 119$ & $156^{*}$ \\
\hline Glu-218 & $2822 \pm 18$ & $154 \pm 2$ & $55^{*}$ & $274 \pm 16$ & $359 \pm 8$ & $1310^{\mathrm{ns}}$ \\
\hline Asn-213 & $3375 \pm 309$ & $270 \pm 30$ & $80 *$ & $2679 \pm 585$ & $103 \pm 23$ & $38 * *$ \\
\hline Gln-213 & $1571 \pm 406$ & $222 \pm 57$ & $141^{\mathrm{ns}}$ & $4400 \pm 794$ & $183 \pm 31$ & $42^{* *}$ \\
\hline Ala-218 & $3377 \pm 917$ & $31 \pm 7$ & $9 * *$ & $4317 \pm 1052$ & $15 \pm 3$ & $3 * * *$ \\
\hline Asn-218 & - & - & - & - & - & - \\
\hline $\begin{array}{c}\text { Asn-213/Asn } \\
218\end{array}$ & & - & - & - & - & - \\
\hline
\end{tabular}

$\mathrm{K}_{\mathrm{m}}$ and $\mathrm{k}_{\text {cat }}$ values are mean \pm SEM from three or eleven separate experiments with duplicate determinations. -,not measurable. $*, p<0.05$, ${ }^{* *}, p<0.01$, ***, $p<0.001$, ns, no significant when compared to the corresponding wild-type values. 


\section{B Biochemical Journal Immediate Publication. Published on 04 Jul 2008 as manuscript BJ20080471}

Fig 1

Wild-type APA in absence of $\mathrm{Ca}^{2+}$

Wild-type APA in presence of $\mathrm{Ca}^{2+}$

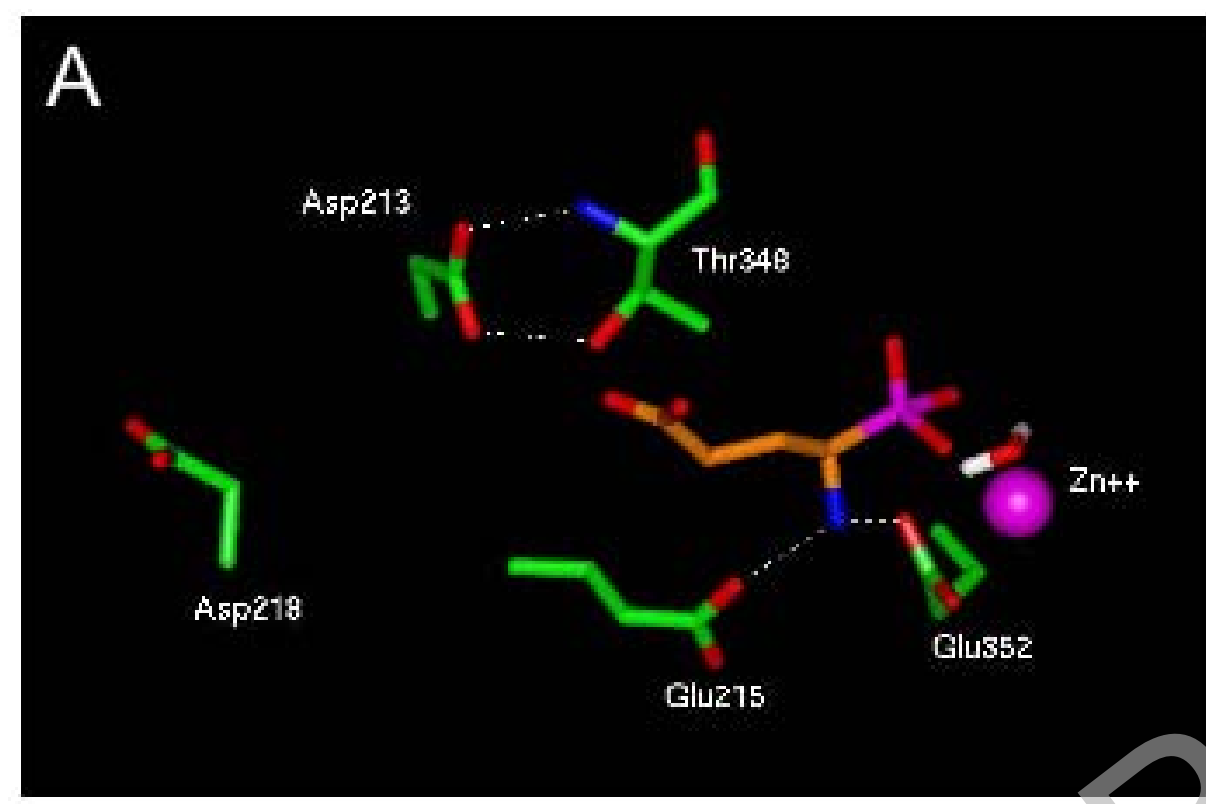

Glu-213 in presence of $\mathrm{Ca}^{2+}$

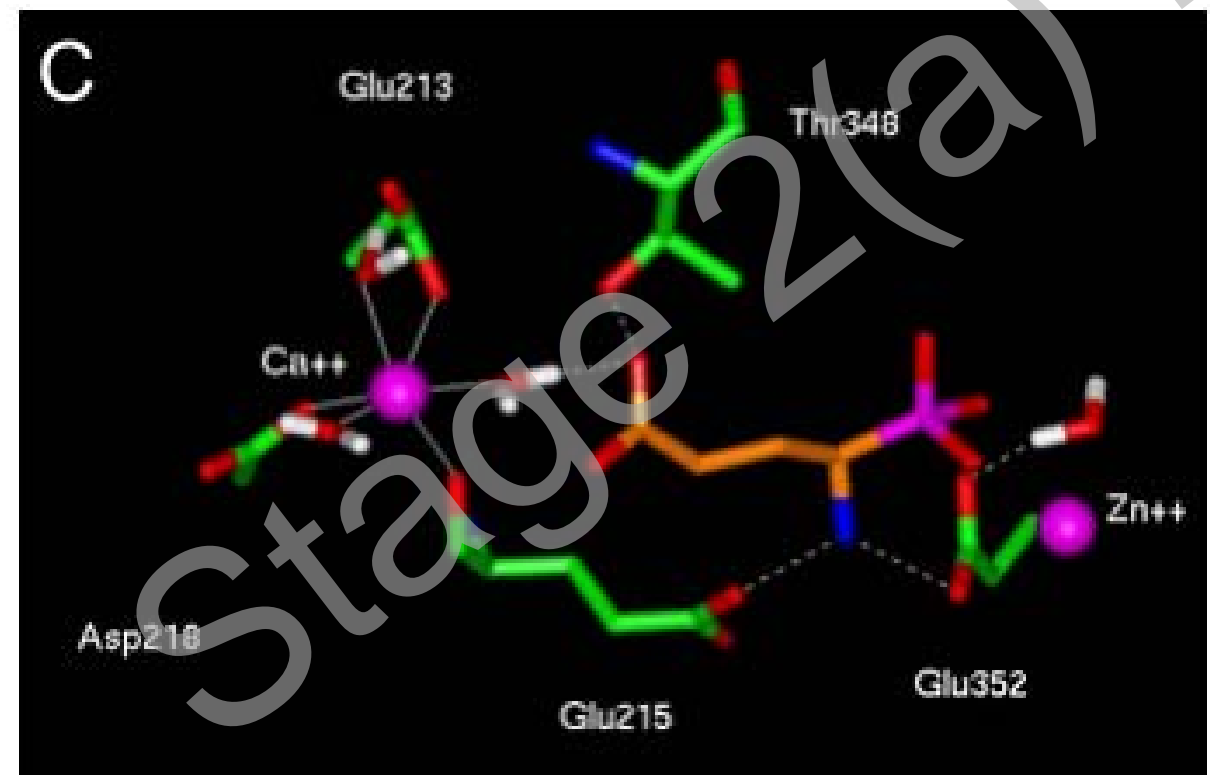

B ז

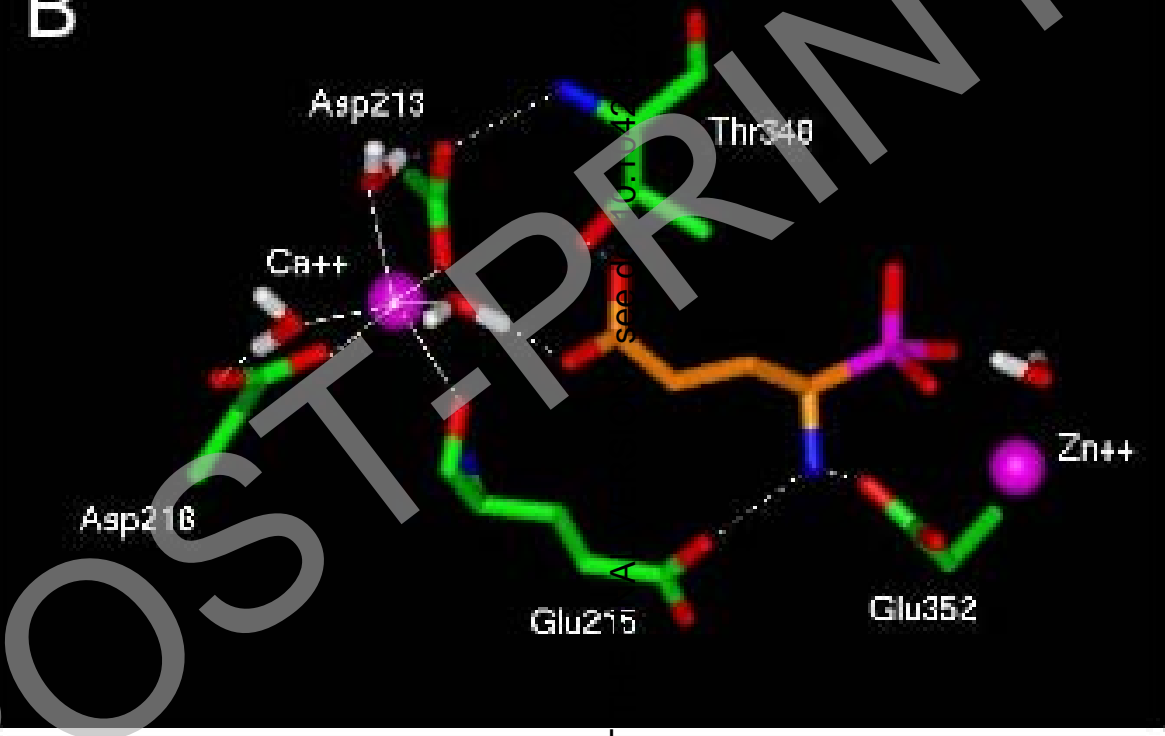

5

Glu-218 in Zुresence of $\mathrm{Ca}^{2+}$

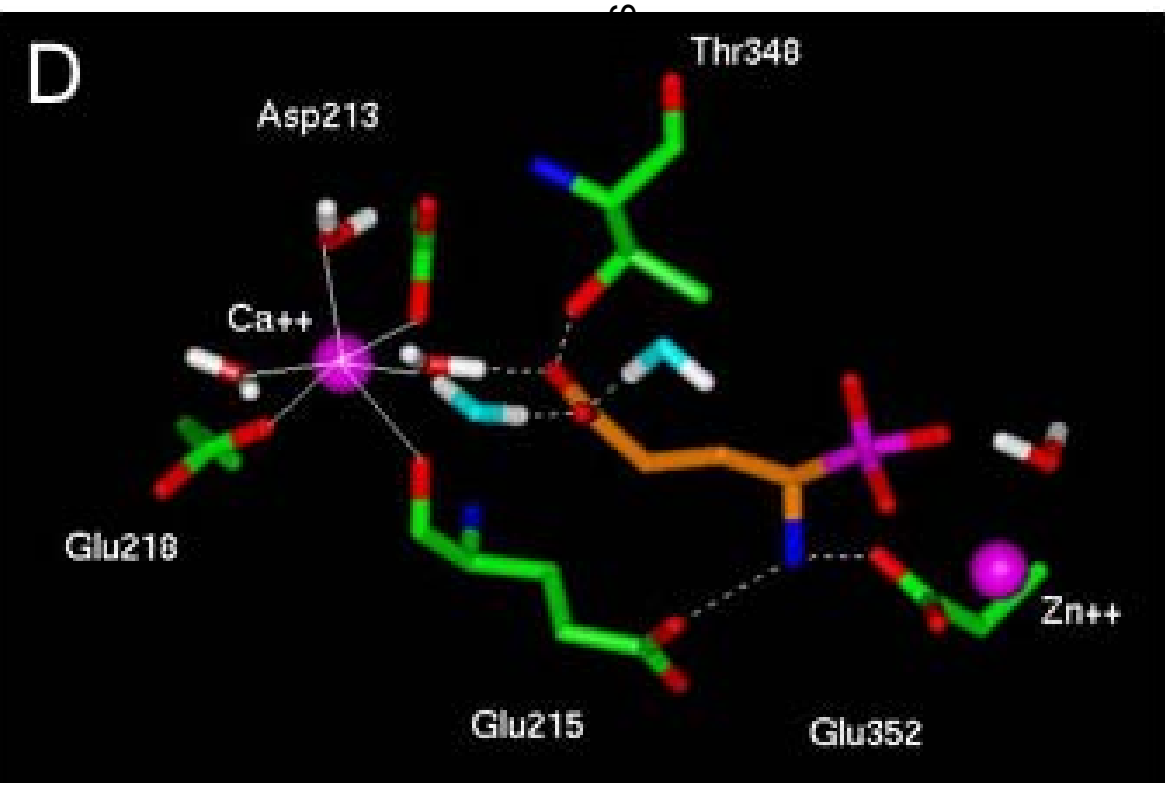

Licenced copy. Copying is not permitted, except with prior permission and as allowed by law.

(C) 2008 The Authors Journal compilation (C) 2008 Biochemical Society 


\section{Fig 2}

A
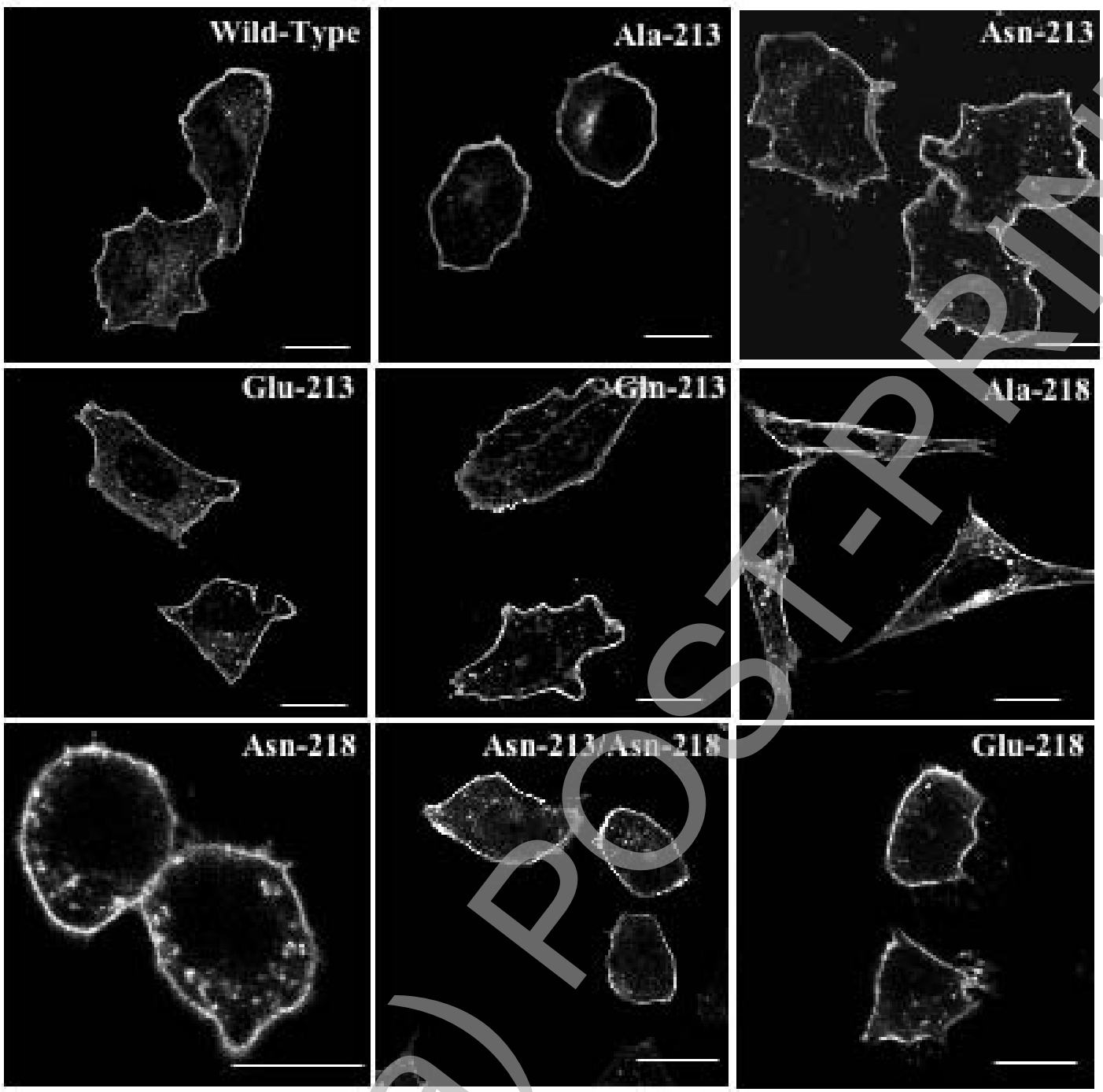

B
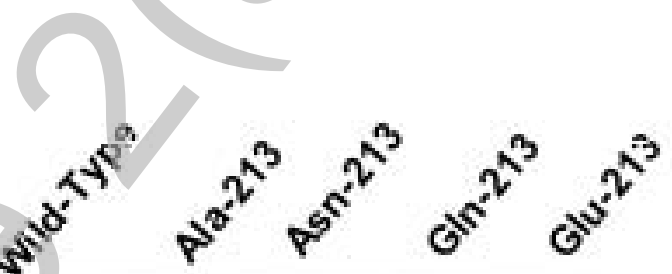

$160 \mathrm{kDa}$
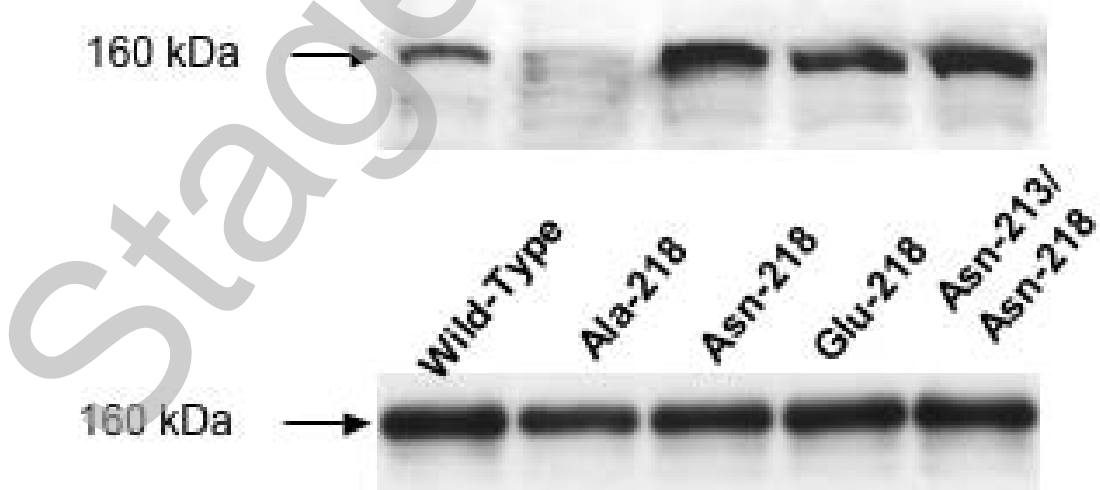

Licenced copy. Copying is not permitted, except with prior permission and as allowed by law.

(C) 2008 The Authors Journal compilation (c) 2008 Biochemical Society 
Fig 3

\section{A - Effect of increasing $\mathrm{Ca}^{2}$ concentration on wild-type, Glu-213 and Glu-218}

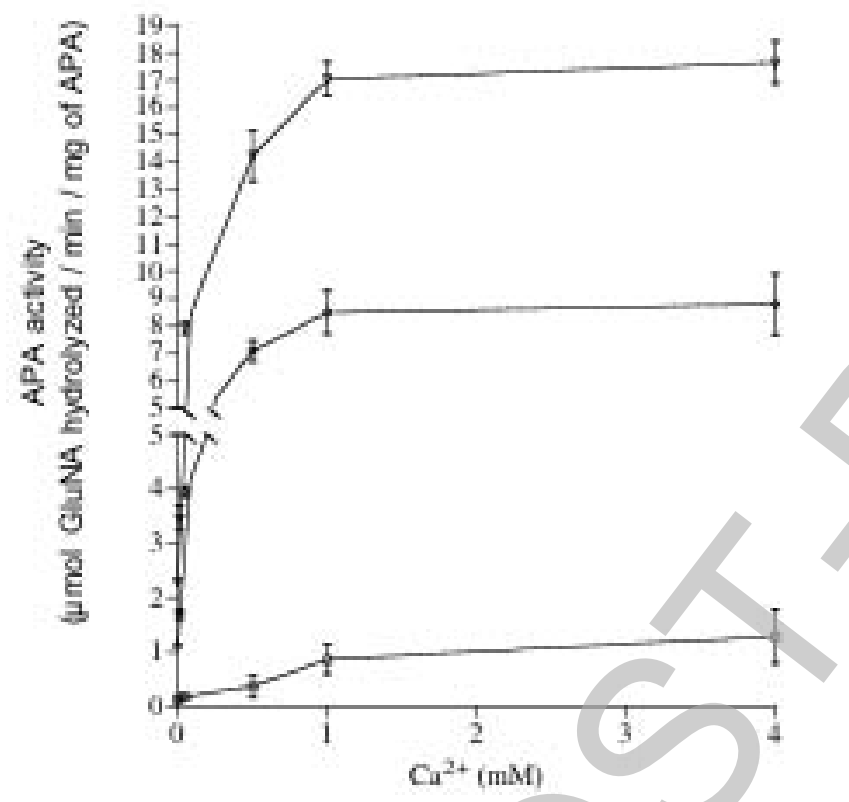

B - Effect of increasing $\mathrm{Ca}^{2}$ concentration on Asn-213, Gln-213 and Ala-218

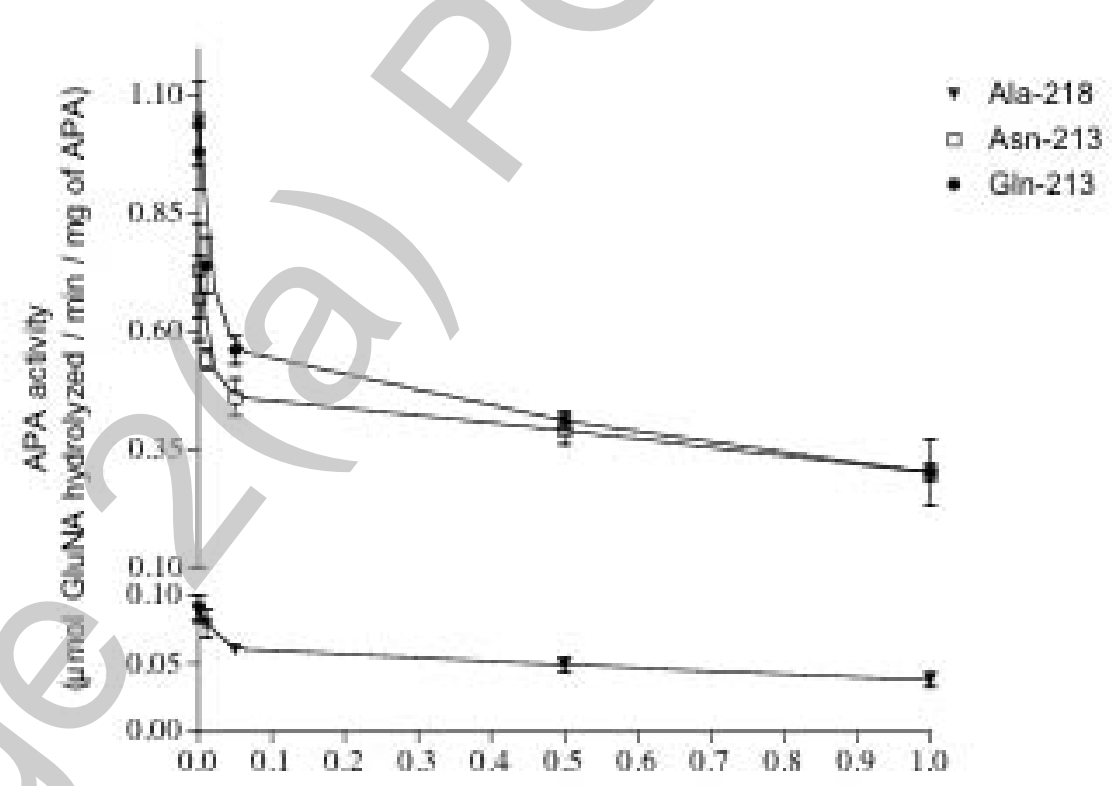

$$
\mathrm{Ci}^{2+}(\mathrm{mM})
$$


Fig 4
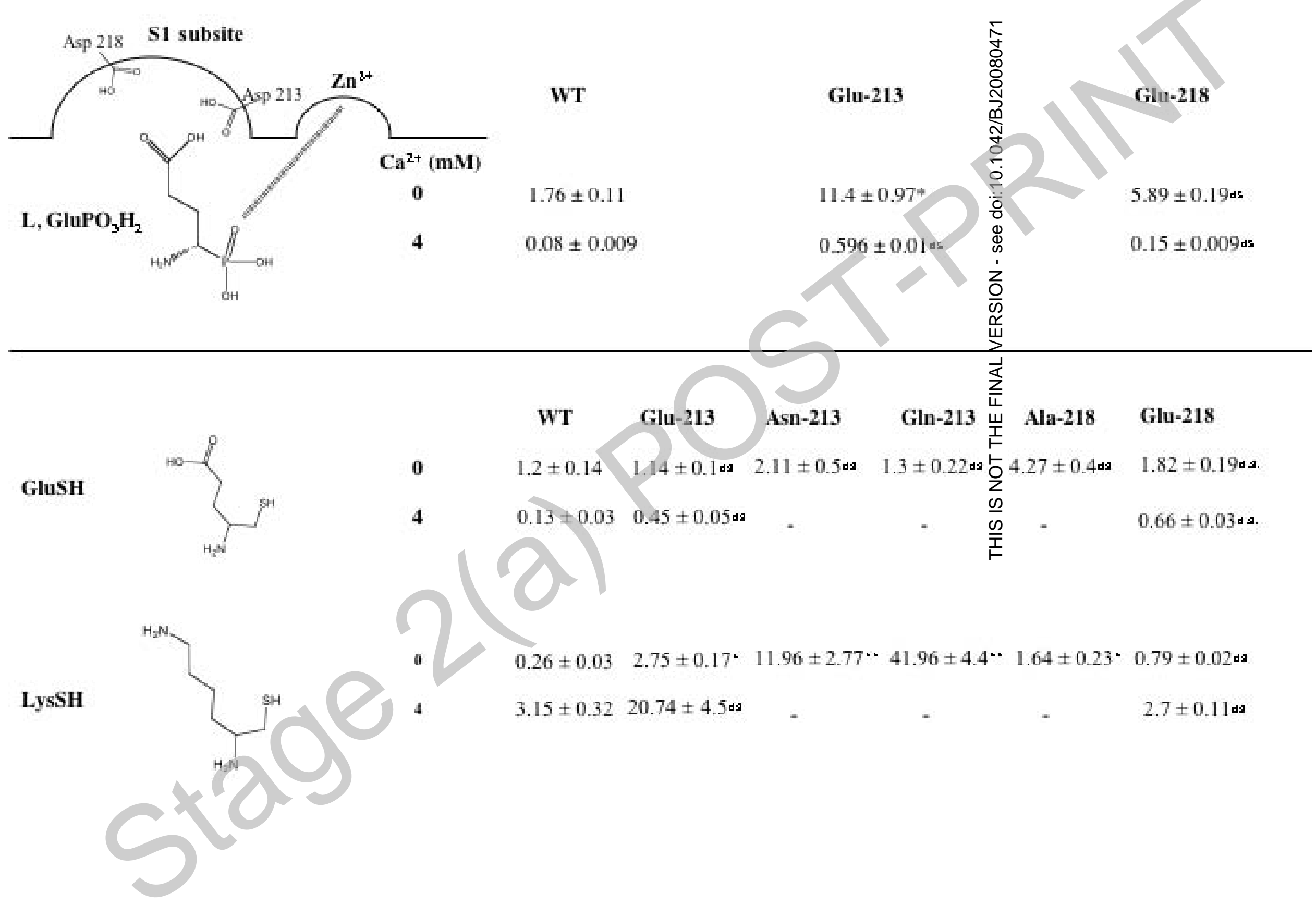

Licenced copy. Copying is not permitted, except with prior permission and as allowed by law.

(C) 2008 The Authors Journal compilation (C) 2008 Biochemical Society 


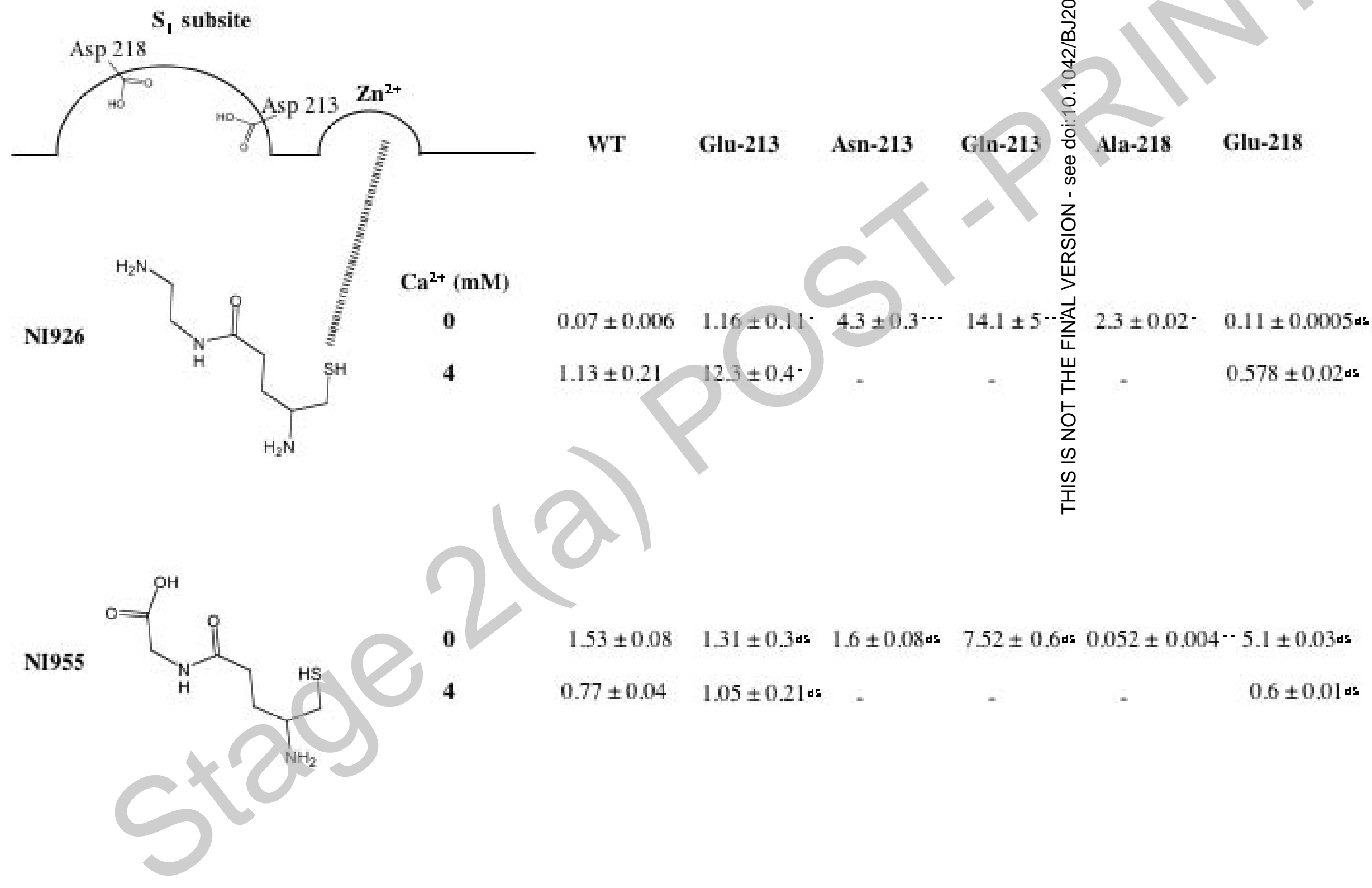

Licenced copy. Copying is not permitted, except with prior permission and as allowed by law.

(C) 2008 The Authors Journal compilation (C) 2008 Biochemical Society 